\title{
Research on the Teaching of Landscape Engineering by Foreign Teachers in Sino-Foreign Cooperative Education in SUCC
}

\author{
Qian Wang*, Yu Gao* \\ Shanghai Urban Construction Vocational College, Shanghai, China \\ *Corresponding authors: Qian Wang,wangqian.sh@hotmail.com; Yu Gao, 982895379@qq.com
}

\begin{abstract}
Sino-foreign cooperative education plays an important role in undergraduate education. It has also proved itself popular in higher vocational education in recent years, in which foreign teachers are undertaking the task of teaching some specialized courses. The teaching by foreign teachers has certain irreplaceable advantages, but nonnegligible disadvantages as well. Questionnaires have been distributed to the students majoring in Landscape Engineering from Shanghai Urban Construction College to investigate the teaching of specialized courses by foreign teachers. Based on the statistics, the advantages and disadvantages of their teaching have been analyzed, and several suggestions on how to adopt the good points and avoid the shortcomings are offered, so as to improve the quality of Sino-foreign cooperative education in higher vocational college.
\end{abstract}

Keywords: Landscape engineering; Teaching by foreign teachers; Sino-foreign cooperative education

Publication date: November 2021; Online publication: November 30, 2021

\section{Introduction}

China is integrating with the world in an unprecedented speed. Many higher vocational colleges are attempting to implement the Sino-foreign cooperative education model ${ }^{[1]}$. By means of international collaboration, Chinese colleges have invited foreign experts from specific fields to teach in China, so as to utilize the high-quality education resources abroad to cultivate Chinese students with international perspectives and English language qualification ${ }^{[2]}$.

The Sino-foreign cooperative education in Shanghai Urban Construction College (SUCC) dates back to the collaboration with Germany, Canada, and the United States (US) in September 2004. Authorized by the Shanghai Municipal Education Commission in 2010, the Sino-US Landscape Engineering Program cooperated with the State University of New York College of Agriculture and Technology at Cobleskill (SUNY Cobleskill). The curriculum has been jointly formulated by both colleges and conforms to the same standard as other cooperative education program. The teaching is carried out bilingually by teachers from both colleges. The core courses of Landscape Engineering have been formulated and taught as shown in Table 1. 
Table 1. Timetable of 2020 Landscape Engineering Program (Sino-US)

\begin{tabular}{cccc}
\hline Term & Course & Period & Teaching Model \\
\hline 2nd & Management of Horticulture Business & 56 & In English by foreign teachers \\
2nd & Turfgrass Cultivation and Management & 56 & Bilingually by both foreign teachers and Chinese teachers \\
4th & Garden Design & 56 & Bilingually by both foreign teachers and Chinese teachers \\
4th & Landscape Flower & 56 & In English by foreign teachers \\
\hline
\end{tabular}

The cooperative education of Sino-US Landscape Engineering Program in SUCC is well designed and has been carried out for nearly 11years. The program is successful and has made many achievements. However, during this course, some difficulties have emerged.

Through questionnaires and statistical analysis, this study analyzes the case of the Landscape Engineering Program in SUCC, so as to make certain contributions to the improvement of Sino-foreign cooperative education in higher vocational colleges in China.

\section{Methods and statistics}

In order to analyze the advantages and disadvantages of foreign teachers' teaching, this research was carried out in three steps: case study, questionnaire, and interview. Firstly, the teaching by foreign teachers was observed and recorded, so as to analyze their methodology. Secondly, the students were questioned, so as to gather their feedbacks in regard to the teaching by foreign teachers, followed by analyzing the figures. Finally, the foreign teachers were interviewed, concerning their expectations of the courses and their final assessment.

The questionnaires comprising of 15 questions each were distributed to 126 students from 2018 to 2020 . A total of 108 questionnaires were valid. The questionnaire mainly investigated the following topics:

\subsection{Do you like the specialized courses by foreign teachers?}

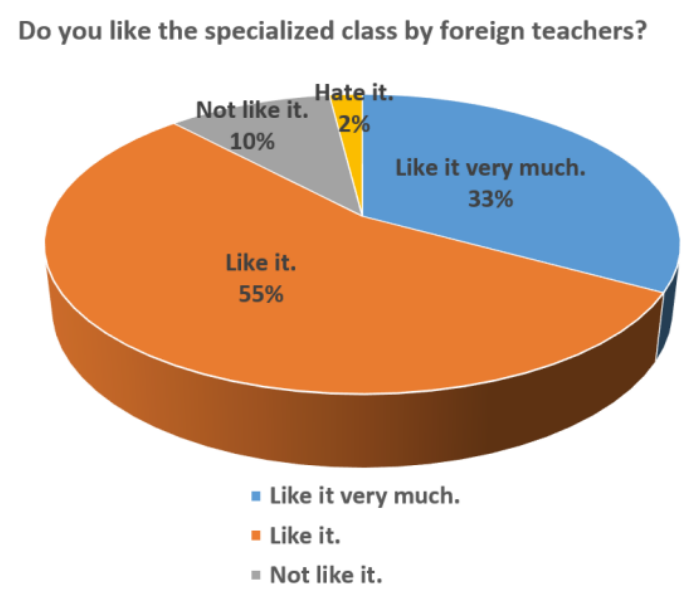

Figure 1. Statistics of topic A

As is shown in Figure 1 above, 55\% of the students liked the teaching of foreign teachers, while 33\% liked it very much. That is to say, almost $90 \%$ of the students gave positive comments on the teaching of foreign teachers. In the follow-up interview, about $80 \%$ students claimed that there were more classes by foreign teachers. 


\subsection{Why do you like the specialized courses by foreign teachers? (multiple)}

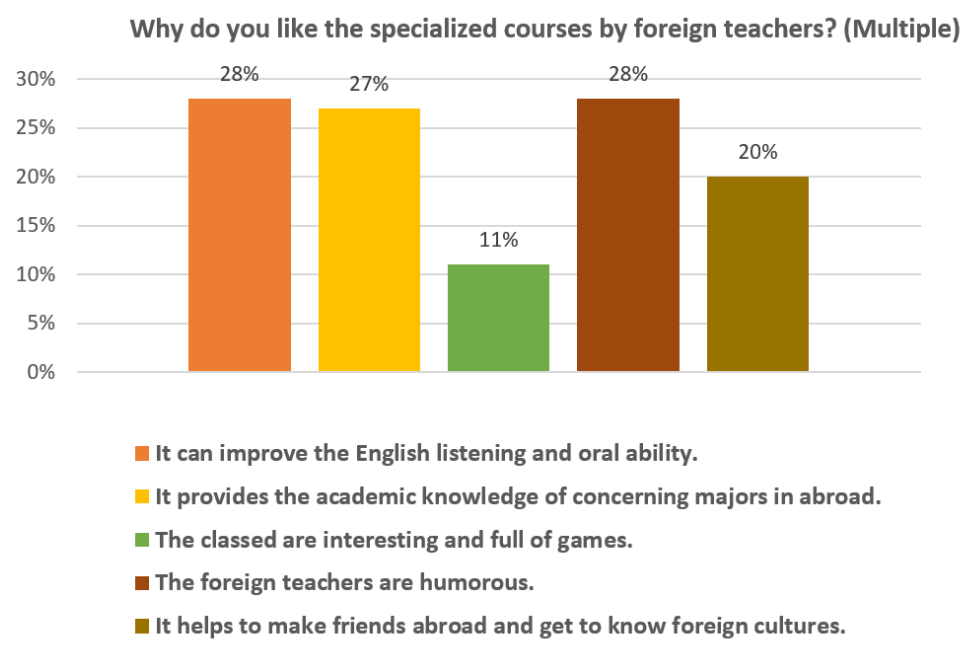

Figure 2. Statistics of topic B

Figure 2 shows the reasons why the students liked the classes held by foreign teachers. The reasons are as follows: helps to improve their English listening and oral ability (28\%); foreign teachers are humorous (28\%); provides the academic knowledge of concerning majors from abroad (27\%); assists the students in making friends abroad and getting to know more about foreign cultures (20\%); classes are interesting and full of games $(11 \%)$.

\subsection{Why do you not like the foreign teachers' classes? (multiple)}

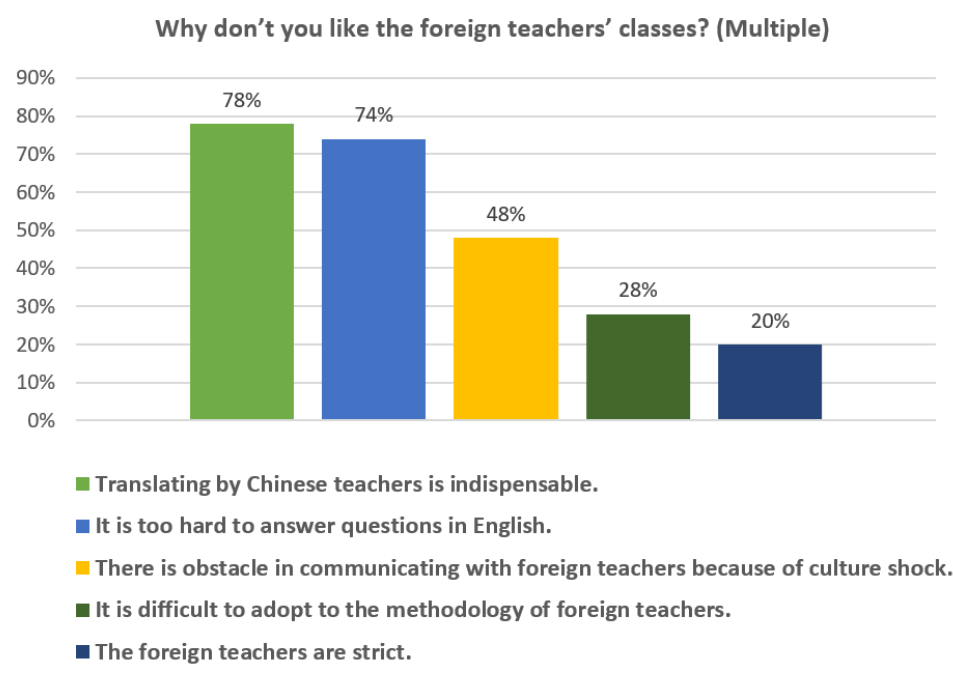

Figure 3. Statistics of topic C

Figure 3 shows the reasons why the students did not like the classes held by foreign teachers. The reasons are as follows: translation by Chinese teachers is indispensable (78\%); it is too hard to answer questions in English (74\%); there are obstacles in communicating with foreign teachers due to culture shock (48\%); it is difficult to adopt to the methodology of foreign teachers (28\%); foreign teachers are strict (20\%). 


\subsection{Is language an obstacle to you in the foreign teachers' class?}

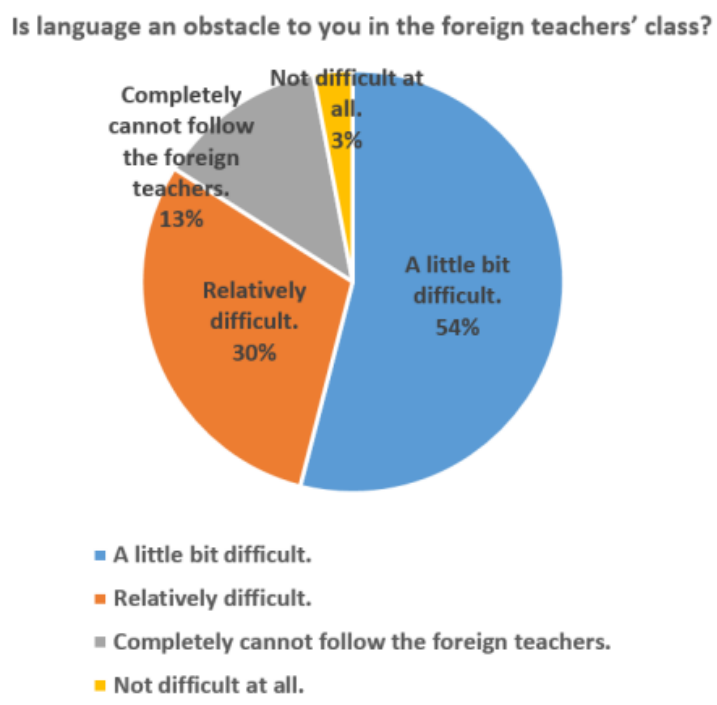

Figure 4. Statistics of topic D

Topic D focuses on the problem of language barrier since the comprehension of the English language is the crux of Sino-foreign cooperative education. Figure 4 shows that $54 \%$ of the students faced language obstacles, while $13 \%$ could not even follow the foreign teachers completely. Only $3 \%$ of the students did not have find language as a challenge.

\subsection{What do you do to handle the language obstacle if you have it?}

What do you do to handle the obstacle of language if you have it?

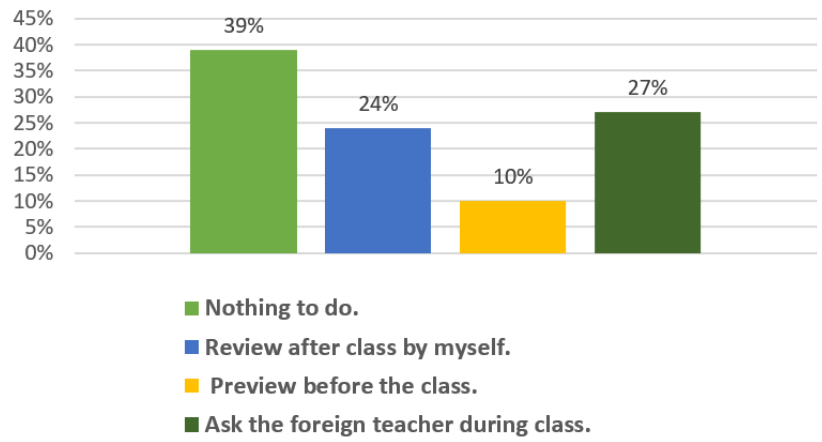

Figure 5. Statistics of topic E

Topic E investigates the attitudes and methods of the students who faced language obstacles. Figure 5 shows that $39 \%$ of the students felt that there was nothing they can do, $24 \%$ of them reviewed what the foreign teachers taught after the classes on their own, $10 \%$ previewed prior to classes, and $27 \%$ asked the foreign teachers during classes. 


\subsection{In what way do you think the specialized courses should be taught?}

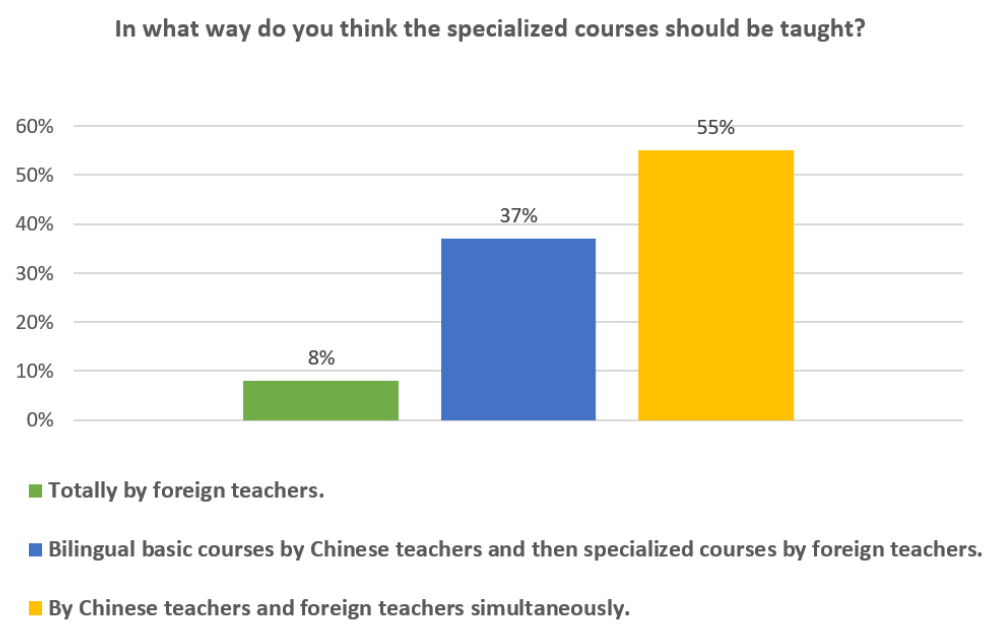

Figure 6. Statistics of topic F

Topic F discusses the ideal way of teaching the Landscape Engineering course in the cooperative education program. As shown in Figure 6, most of the students $(55 \%)$ thought it would be better if the courses were taught simultaneously by both Chinese teachers and foreign teachers. $37 \%$ of the students felt that Chinese teachers should teach the basic courses bilingually in advance and then the specialized courses by foreign teachers, wholly in English. 8\% students would like to have the specialized courses completely taught by foreign teachers.

Besides, 16 teachers from SUCC and SUNY Cobleskill were interviewed, concerning the existing state and suggestions for improving future cooperative education.

\section{Findings}

The teaching methods used by foreign teachers vary. They are vivid and flexible, reflecting the philosophy of the famous American educationalist, John Dewey - "To learn from practice." For example, in the Landscape Design course, students were to draft and color landscape flowers in a creative manner on their own. They were encouraged to go around their campus to observe specific plants. These practical activities would promote the students to come into contact with the world and gain experiences in person ${ }^{[3]}$.

Some foreign teachers prefer to divide the students into groups of four to six students, in order to carry out activities and hold discussions. This method would effectively strengthen the communication among students as well as the interaction between teachers and students ${ }^{[4]}$. Within the groups, top achievers can help out the students who are below average at any time, so that each student would be effectively and positively involved in class activities. At times, the quiz given at the beginning of each period would be discussed within the groups after individual submission.

Other foreign teachers use case study during classes. The cases are meticulously designed in accordance with the teaching content and formulation, so as to offer a dimensional thinking space for the students. In this way, students would be more engaged, pondering about the topics and raising queries ${ }^{[5]}$.

Academic specialty is another strong point of foreign teachers. The original edition English textbooks and relevant cases with international advantages would broaden students' horizon and expand their specialties ${ }^{[6]}$. Besides, the varied and dynamic teaching styles of foreign teachers are welcomed by students. Meanwhile, foreign teachers feel that their classes bring different perspectives from other foreign scholars. As to language factor, students with a comparatively higher English competence benefit greatly from those 
specialized classes because foreign teachers are native English speakers who are capable in utilizing standard English.

The disadvantages of foreign teachers' teaching are discussed below.

\subsection{Language barrier}

Most students in vocational colleges are unable to utilize English to communicate with foreign teachers on certain topics in the course. 54\% of the students faced language obstacles and majority of them were not able to find a proper way to handle it. That is why some students may feel that the theoretical part of those classes is boring.

\subsection{Gaps in the continuation of the course}

Due to the language barrier, the subject courses taught by foreign teachers are not as deep as being taught by Chinese teachers. Therefore, there are inevitable gaps between preceding courses and the follow-up courses taught by foreign teachers.

\subsection{Cultural differences}

Due to different cultural backgrounds, some students are not able to adjust to the teaching methods and way of communication by foreign teachers, even to the extent of feeling confused or pressured. For example, $48 \%$ of the students in this study experienced culture shock along with barriers in communication with the foreign teachers. There are also students who cannot accept that there are no make-up examinations and that those students who have failed need to commit to the course the following year and retake the examination.

\subsection{High cost}

The budget for the Sino-US cooperative education is high due to the higher teaching fees and living costs of foreign teachers.

\section{Discussion}

According to the statistics and corresponding analysis, it is easy to appreciate that the current cooperative teaching model needs to be reformed and it is necessary to establish a compound teaching model so as to improve the teaching quality.

\subsection{Setting up specialized English language courses and preceding bilingual courses in advance}

The subject courses taught by foreign teachers include a large number of English terminologies; thus, it is an obstacle for students to follow the courses in English if they are unable to comprehend those terms. Therefore, it would be helpful for students to attend preceding bilingual courses and specialized English courses before the subject courses ${ }^{[7]}$. In that way, students would have already mastered specialized terms and their special usages prior to the subject courses. For example, Landscape Charting and Sketching Skills are preceding courses to Landscape Design. Therefore, these two courses could be taught bilingually, so that students would learn most of the terms used in Landscape Design. With the help of those terms, students would be able to understand the terms used by foreign teachers easily. Students also welcome Chinese teachers to teach the preceding courses bilingually before the courses that are completely taught in English by foreign teachers. 
Foreign teachers have suggested that there should be a language test and only those students who have reached a certain standard in English would be allowed to attend the courses taught by foreign teachers. The Standard English Test can urge the students to improve their English skills in terms of listening, oral, writing, and comprehensive reading, thus guaranteeing the quality of teaching in English.

\subsection{Dynamic integration of foreign teachers and Chinese teachers}

The dynamic integration of foreign teachers and Chinese teachers is seemingly the most suitable model for specialized courses in view of the Sino-foreign cooperative education in higher vocational colleges ${ }^{[8]}$. Chinese teachers can timely interpret for the students according to real situations and the difficulty index. Besides, Chinese teachers can guide the students to preview the teaching materials and explain certain terms to them. Additionally, Chinese teachers can also help the students to list out several questions, so as to increase the effect of foreign teachers' lectures. Chinese teachers should select proper bilingual textbooks, formulate teaching contents, and supplement teaching materials in line with students' professional English levels ${ }^{[9]}$.

\subsection{Tutorial teachers to assist students}

Foreign teachers generally emphasize practicing, discussing, and teamwork in class, which are not common for students who are accustomed to traditional lecturing lessons. Tutors can organize meetings or face-toface talks for students to encourage them to communicate better with foreign teachers and ease their pressure.

\subsection{Communication between foreign teachers and Chinese teachers}

Sino-foreign cooperative education needs compound teamwork from both foreign teachers and Chinese teachers, not only for key courses, but also other relative specialized courses. Foreign teachers need to know the English level of the students, so that they can implement proper teaching methods. Meanwhile, Chinese teachers need to be familiar with the teaching objectives so as to assist the foreign teachers.

\section{Conclusion}

This study has sought to investigate the teaching of foreign teachers in the Sino-US Landscape Engineering Program in SUCC. According to the statistics and interview in this study, the advantages of the classes conducted by foreign teachers can be summed up as follows: helpful for students to practice their English listening and oral skills; a good way to understand the professional academic knowledge abroad; foreign teachers are humorous, and their classes are interesting; provide access to foreign culture and people.

On the other hand, the disadvantages of classes taught by foreign teachers are as follows: difficult for students to follow the lectures which are completely taught in English; students are not able to answer the questions in English; there are obstacles in communicating with foreign teachers due to culture shock; difficult to adopt to the teaching methods of foreign teachers.

When it comes to future cooperation, it would be better to set up specialized English language courses and preceding bilingual courses in advance. Chinese teachers, tutorial teachers, and foreign teachers should closely cooperate with each other.

This study questioned and interviewed 108 students majoring in Landscape Engineering from Shanghai Urban Construction Vocational College and 16 teachers from SUNY Cobleskill and SUCC. The study sample did not cover other cooperative education programs or other vocational colleges. This is the limitation of this study, and it is also the direction of future research. It is wise to adopt the good points but avoid the shortcomings of the cooperative education, so as to improve the quality of the Sino-foreign 
cooperative education in China.

\section{Acknowledgements}

We would like to thank all the teachers and students from Shanghai Urban Construction Vocational College and the State University of New York College of Agriculture and Technology at Cobleskill, who have been questioned and interviewed for this study. We would also like to thank Michael Liu from the Information Technology Department for his valuable support with the statistics and quantitative analysis.

\section{Disclosure statement}

The authors declare that there is no conflict of interest.

\section{References}

[1] Zhong P, 2019, 2019 International Conference on Social Science, Management and Education (ICSSME 2019), 2019: The Application of Cooperative Learning Teaching Method in the Teaching of "Audit Training" Course in Higher Vocational Education, Tokyo, 132-136.

[2] Pakpahan NFDB, 2018, Learning Outcomes Through the Cooperative Learning Team Assisted Individualization on Research Methodology' Course. IOP Conference Series: Materials Science and Engineering, 296: 67-71.

[3] Jia XL, 2017, 2nd International Conference on Education \& Educational Research and Environmental Studies, 2017: On the Cooperative Learning in College English Teaching, Sapporo, 28-32.

[4] Pinner Richard S, 2021, Exploratory Practice in Language Teaching: Puzzling About Principles and Practices. Educational Action Research, 229: 73-77.

[5] Paolo I, Peter L, 2021, Scientific Discursive Practices in a Bilingual Middle School Science Classroom. International Journal of Bilingual Education and Bilingualism, 24(7): 913-926.

[6] Kaan E, Grüter T, 2021, Prediction in Second Language Processing and Learning: Advances and Directions, in Kaan E, Grüter T (Eds.), Prediction in Second Language Processing and Learning, John Benjamins, Publishing Company, Amsterdam.

[7] D'Souza D, D’Souza H, 2021, Bilingual Adaptations in Early Development. Trends in Cognitive Sciences. 25(9): 727-729.

[8] Sandberg WC, Monika Z, Gray T, 2021, Bilingual Abstract Semantic Associative Network Training (BAbSANT): A Polish-English case study. Journal of Communication Disorders. 93: 106-143.

[9] Sharky B, 2016, Thinking about Landscape Architecture: Principles of a Design Profession for the 21st Century (English Edition), Routledge, London. 